\title{
Fixed Dose Combination Therapy of Antioxidants in Treatment of Idiopathic Oligoasthenozoospermia: Results of a Randomized, Double-blind, Placebo-controlled Clinical Trial
}

\author{
PM Gopinath, Bharti Kalra, Ajit Saxena, Sonia Malik, Kapil Kochhar, Sanjay Kalra, Hemant Zaveri
}

\begin{abstract}
Introduction: To assess the effectiveness and safety of fixed dose combination (FDC) of antioxidants in treatment of idiopathic oligoasthenozoospermia.
\end{abstract}

Materials and methods: Placebo-controlled, Double-blind, randomized, Parallel three arm, Multicentric trial.

Setting: Fertility clinics of five centers across India.

Patients: One hundred and thirty-eight male subjects, aged between 21 and 50 years and subfertile for 1 year or more with the following baseline sperm selection criteria: Concentration $<15 \mathrm{million} / \mathrm{ml}$ and total sperm motility $<40 \%$.

Intervention(s): Eligible subjects were randomized to either of the three arms in a double-blind manner, i.e. arm 1 was given 2 tablets twice daily of FDC of antioxidants (coenzyme-Q10: $50 \mathrm{mg}$, L-carnitine: $500 \mathrm{mg}$, lycopene: $2.5 \mathrm{mg}$ and zinc: $12.5 \mathrm{mg}$ ); arm 2 was given 1 tablet of FDC of antioxidants and one tablet of placebo twice daily and arm 3 was two tablets twice daily of matching placebo all for 180 days.

Main outcome measure(s): The primary outcome measures were improvement in sperm count and sperm motility, whereas pregnancy rate was the secondary efficacy outcome.

Results: Compared to placebo, a statistically significant improvement was seen in sperm count (14.8-26.35 in arm 1 and 14.37-24.8 million/ml in arm 2, p < 0.0001), and sperm total motility (39.2-51.6\% in arm 1 and 38.4-50.1\% in arm 2, p < $0.0001)$, at 90 days, and treatment further improved these parameters at day 180 . No intergroup difference was seen between arm 1 and arm 2. Mild adverse event of upper gastrointestinal discomfort by 8 subjects (three in arm 1; one in arm 2 and four subjects in arm 3) were reported. No serious adverse event was seen in the study.

Conclusion: Exogenous administration of fixed dose combination of antioxidants is a safe and effective therapy in improving the male subfertility.

Keywords: Oligospermia, Asthenozoospermia, Ubiquinone (coenzyme Q10), L-carnitine, Zinc, Lycopene.

How to cite this article: Gopinath PM, Kalra B, Saxena A, Malik S, Kochhar K, Kalra S, Zaveri H. Fixed Dose Combination Therapy of Antioxidants in Treatment of Idiopathic Oligoasthenozoospermia: Results of a Randomized, Doubleblind, Placebo-controlled Clinical Trial. Int J Infertility Fetal Med 2013;4(1):6-13.

Date of Received: 14-12-12

Date of Acceptance: 18-03-13

Date of Publication: January 2013

\section{Source of support: Nil}

Conflict of interest: None

\section{INTRODUCTION}

Worldwide, more than 70 million couples suffer from infertility and the majority of these reside in developing countries. Male subfertility may be contributing to total infertility in large. ${ }^{1-4}$ Male subfertility can be the result of congenital urogenital anomaly, infections of the testes or tract, increased scrotal temperature, endocrine disturbances, genetic abnormalities and immunological factors; ${ }^{5}$ however idiopathic male subfertility is found in 30 to $75 \%$ of cases. ${ }^{6}$ Semen analysis of subfertility cases often reveals a decreased number of spermatozoa (oligozoospermia), decreased motility (asthenozoospermia) and many abnormal forms on morphological examination (teratozoospermia). These abnormalities usually occur together and are described as the oligoasthenozoospermia syndrome.

A growing body of evidence shows deleterious role of reactive oxygen species and other oxidative radicals on human sperm. ${ }^{7,8}$ Oxidative injury is observed to be possibly causing the damage of sperm membrane and fragmentation of DNA either at nuclear or mitochondrial levels.

Micronutrients, such as coenzyme Q10 (CoQ10) and L-carnitine have been found as components of the mitochondrial respiratory chain that plays a crucial role both in energy metabolism and as liposoluble chain-breaking antioxidants for cell membranes and lipoproteins. ${ }^{9,10} \mathrm{CoQ} 10$ biosynthesis is markedly active in testis, ${ }^{11}$ and high levels are present in sperm, ${ }^{12-14}$ suggesting a protective role as antioxidant. Some groups have demonstrated reduced levels of CoQ10 in seminal plasma and sperm cells of infertile men with idiopathic and varicocele-associated asthenoszoopermia. ${ }^{15}$ On this basis, CoQ10 is considered one of the compounds contributing to the total antioxidant buffer capacity of semen, and its decreased levels are deleterious to the system in dealing with oxidative stress. ${ }^{16,17}$

L-carnitine also has antioxidant characteristics that protect sperm against toxic free radical species. Studies ${ }^{18,19}$ have demonstrated the effectiveness of L-carnitine in 
treating male subfertility due to idiopathic or microbial infections by increasing sperm count, motility and semen volume significantly. Carnitine decreases oxidative stress via interaction with arachidonic acid incorporation into phospholipids and protein kinase C-mediated NADPH oxidase system. ${ }^{20}$ It is also proposed that carnitine exerts antioxidant properties as a result of repairing mechanism by which elevated intracellular toxic acetyl-CoA is removed and fatty acids in membrane phospholipids are replaced.

Lycopene is natural occurring carotenoids that have very potent free radical scavenger properties during oxidative stress, ${ }^{21,22}$ and may play a major role in prevention of oxidative sperm injury.

Zinc had a documented role in testosterone formation, and low zinc intake may be an important etiology for low sperm counts quality of sperm ${ }^{23}$ and idiopathic male subfertility.

Though, previously studies have shown the benefits of CoQ10, ${ }^{24-27}$ L-carnitine, ${ }^{28-30}$ lycopene ${ }^{31-32}$ and zinc ${ }^{33,34}$ as an individual agent in male subfertility, but so far studies are lacking on its combinational use in male subfertility in Indian population. Therefore, the current study was designed to evaluate the safety and effectiveness of FDC of seminal antioxidants in subjects of idiopathic oligoasthenozoospermia in a randomized double-blind manner.

\section{MATERIALS AND METHODS}

The study was approved by Independent Ethics Committee (IEC) for each center and was conducted in accordance with ICH-GCP and declaration of Helsinki rule and was registered in clinical trial registry of India. Before initiation of the study, training was imparted to all the participating centers to keep uniformity in study methods and data collection. All subjects were enrolled in the study after obtaining their written informed consent. Trial were registered to CTRI and registration number were CTRI/ 2010/091/000574.

\section{Study Population}

One hundred and thirty-eight subjects (mean age: 30.74 years, range: 24-45 years) affected by idiopathic oligoasthenozoospermia were enrolled in the study. The subjects were selected at the fertility clinics of five centers across India, i.e. Sooriya Hospital, Saligramam, Chennai; Menz Health Clinic, Noida, UP; Bharti Research Institute of Diabetes and Endocrinology (BRIDE), Karnal, Haryana; Men's Health Clinic, Indore, MP and Southend Fertility and IVF Centre, Holy Angels Hospital, New Delhi, India. All subjects presented with clinical history of primary infertility for $>1$ year were underwent medical screening, including history and clinical examination. Each subject was evaluated for testicular volume; varicocele; any anatomic abnormalities of testicular, seminal vesicle and prostatic using ultrasonography; venous spermatic plexus using echocolor Doppler; sperm culture, urethral specimen culture; semen analysis; antispermatozoa antibodies; FSH, LH, prolactin, estradiol and testosterone assay using RIA kits.

A due care was given to rule out any female factor involvement, since all the female partners of participating subjects were undergone ultrasound evaluation for ovary, uterus and fallopian tube anatomy during hysterosalpingography and were free from any abnormalities and ovulated regularly, as formally proved by biphasic basal body temperature and luteal phase progesterone levels. All women denied sexual involvement with another male partner.

\section{Inclusion and Exclusion Criteria}

The following criteria were adopted for subjects' eligibility: male subjects with age 21 to 50 years, infertility $>1$ years, sperm count less than 15 million/ml, sperm total motility $<40 \%,{ }^{35,36}$ no history of taking therapy for infertility, no history of obstructive azoospermia and regular sexual intercourse with a potentially normal fertile female, willing to sign informed consent and likely to be available for all visits during follow-up period.

Subjects with primary testicular disease, any organic cause for infertility including varicocele, prostato-vesiculoepididymitis, genital infectious disease, planning for any other assisted reproductive techniques (ART) during the study period, serum follicle stimulating hormone FSH $>15 \mathrm{mIU} / \mathrm{ml}$, abnormal serum levels of LH, testosterone, estradiol and prolactin, presence of antispermatozoa antibodies, severe oligospermia $(<2$ million sperm $/ \mathrm{ml})$, azoospermia, seminal white blood cells (WBCs) more than $1 \times 10^{6} \mathrm{ml}$, major hepatic and renal disease, myopathy, history of allergy to any ingredient of the formulation, not likely to be available for follow-up, have participated in another clinical trial in the past 3 months and female partners with anatomic or physiological alterations causing subfertility were excluded from the study.

\section{Study Design and Treatment}

Subjects matching all the inclusion and exclusion criteria on screening were centrally randomized to one of three treatment arm (arm 1-3), in a 1:1:1 ratio; arm 1 subjects received 2 tablets of FDC antioxidants twice daily, arm 2 subjects received 1 FDC tablet +1 placebo tablet twice daily and arm 3 subjects received 2 tablets of placebo twice daily. 
FDC tablets of antioxidants, (Co-Q10 $50 \mathrm{mg}$, L-carnitine $500 \mathrm{mg}$, zinc $12.5 \mathrm{mg}$ and lycopene $2.5 \mathrm{mg}$ ) and its matching placebo tablets were manufactured by Zydus Cadila Ltd, Ahmedabad, India. All the subjects were followed up at 3 and 6 months of therapy, and further 6 months follow-up if required. Semen analysis was carried out as recommended by the World Health Organization, $2010 .{ }^{36}$ Subject compliance and possible side effects were also noted at each visit. The primary efficacy endpoint identified was improvement in sperm count, and sperm motility over baseline compared to placebo. The secondary efficacy endpoint was pregnancy rate.

\section{Semen Analysis}

Semen was collected by masturbation after 2 to 3 days of sexual abstinence. Semen analyses were done at baseline, 90 days after enrollment and 180 days after enrollment. A validated and standard laboratory was used in the study for collection and analyses of the semen (manual results were calculated for sperm concentration or count). For motility evaluation percentage of sperm with WHO A, B, C or D motility was assessed by WHO 2010 guidelines criteria. $^{36}$

\section{Statistical Analysis}

Descriptive statistics were computed for demographic and seminal parameters and a statistical comparison was made for seminal parameters. Paired t-test was used to calculate statistical difference between the days 90 and 180 from baseline (day 0). The change from baseline (day 0) in sperms parameter on day 90 and 180 was calculated. Analyses of covariance (ANCOVA) model was used to evaluate the least square mean change from baseline which includes treatment as fixed effect and baseline (day 0) as covariate. Changes were presented using the least-square means derived from the ANCOVA model. A comparison between treatment groups was made using the difference in least-square means and p-values from the ANCOVA model. All the statistical analyses were performed using Statistical Analysis System (SAS) Statistical Package (version 9.1; SAS Institute Inc Cary, North Carolina, 27513-2414 USA).

\section{RESULTS}

Of the 200 subjects screened, 138 were enrolled in the study (46 subjects randomized in each group), whereas only 125 (46, 43 and 36 in arms 1, 2 and 3 respectively) completed the study and 13 subjects were lost to follow-up at different stage during the study. The subjects enrolled in this study are for more in number than any of the historic trial with the similar conditions. Data analysis was performed on
125 subjects who completed the entire duration of study. Disposition of the study population is shown in Figures 1 to 4. Demographic characteristics of enrolled subjects are given in details in Table 1 . The baseline characteristics of enrolled subjects were statistically comparable in all the three arms: Arm 1 (2 tablets of antioxidant FDC, twice daily), arm 2 (1 tablet of FDC +1 tablet of placebo, twice daily) and arm 3 (2 tablets of placebo, twice daily).

\section{Seminal Analysis}

Results showed statistically significant improvement in sperm count (increase from 14.8 to 26.35 in arm 1 and 14.37 to $24.8 \mathrm{million} / \mathrm{ml}$ in arm $2, \mathrm{p}<0.0001$ ) and sperm motility (39.2-51.6\% in arm 1 and 38.4-50.1\% in arm 2, p < 0.0001) in both the treatment arms, at day 90 as compared to their baseline value at day 0 , whereas small improvement in seminal parameters was also seen in placebo group (Table 2 and Fig. 2). Treatment for 180 days further improved the seminal parameters over the baseline in both the arms 1 and 2. Furthermore, compared to placebo, improvements in seminal parameters were significantly much more in both the arms of treatment (arm 1 as well as arm 2; Table 3). However, no intergroup difference was seen between the

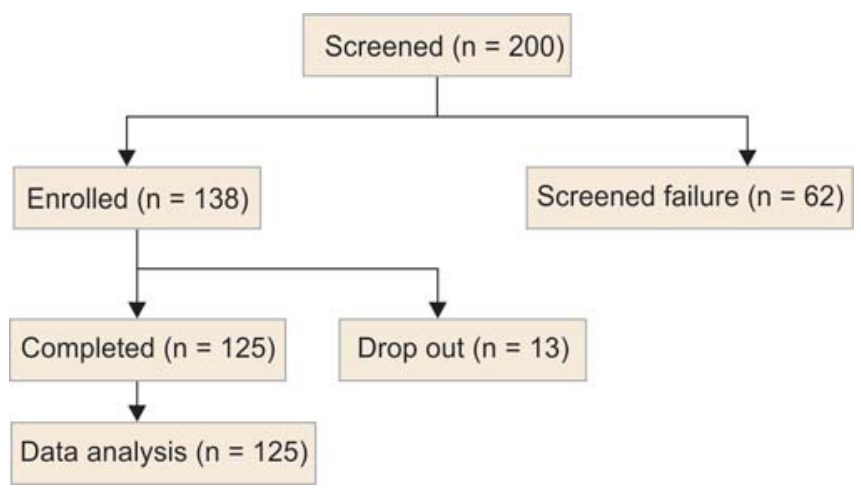

Fig. 1: Disposition of study subjects

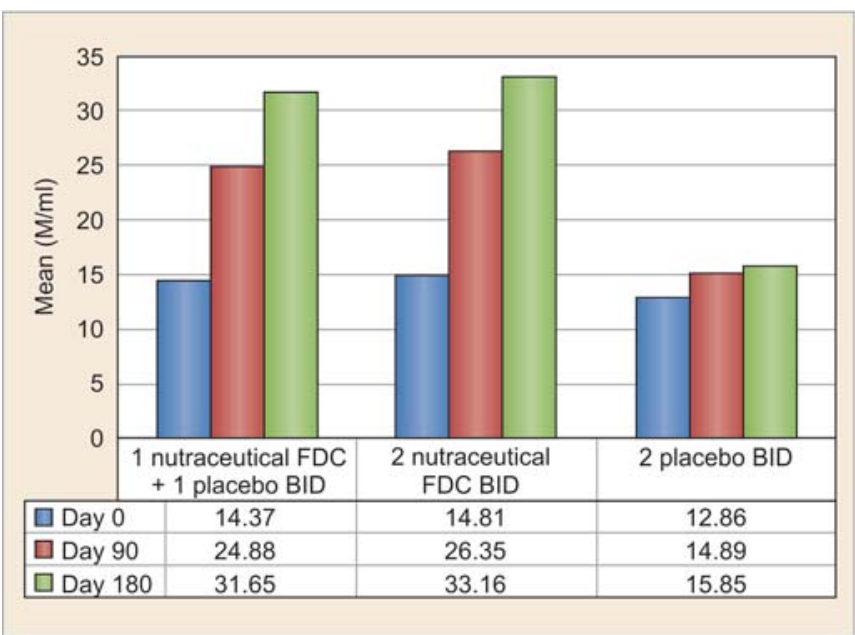

Fig. 2: Sperm count (million/ml) in each arm 
two-treatment arms (arm 1 and arm 2) on any of seminal parameters (Table 3).

\section{Spontaneous Pregnancies}

A total of 15 spontaneous pregnancies observed during the study (6 pregnancies in arm 1 and 7 pregnancies in arm 2, and 2 pregnancies in arm 3) (Table 2). Four pregnancies in arm 1 occurred after 3 months and 2 after 5 months, whereas

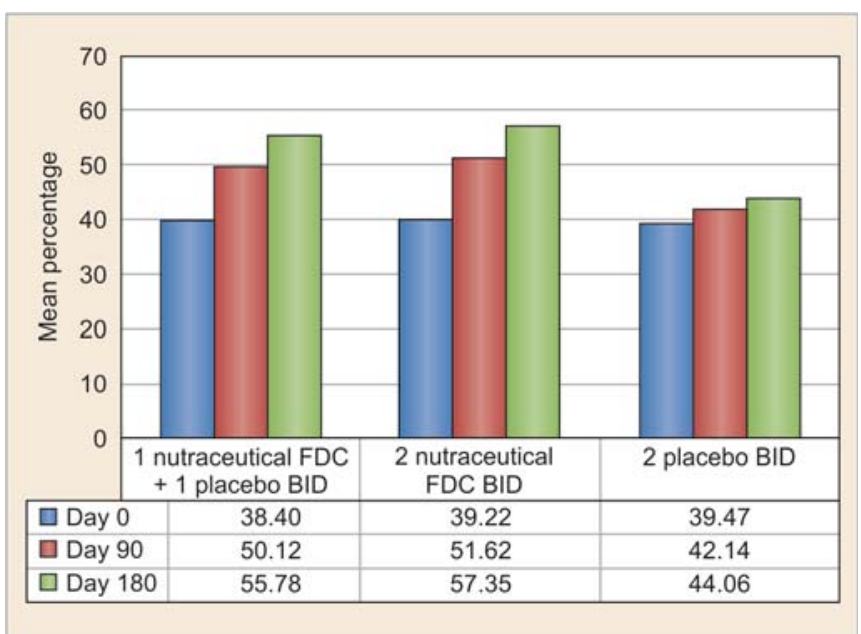

Fig. 3: Motile sperm (\%) in each in arm 2, two pregnancies occurred after 2 months, 3 after 3 months and 2 after 4 months. Of the 2 pregnancies of placebo group, one occurred after 4 months and one after 5 months.

\section{Safety Assessments}

No serious adverse event was observed in the study. Mild adverse event of upper gastrointestinal discomfort by

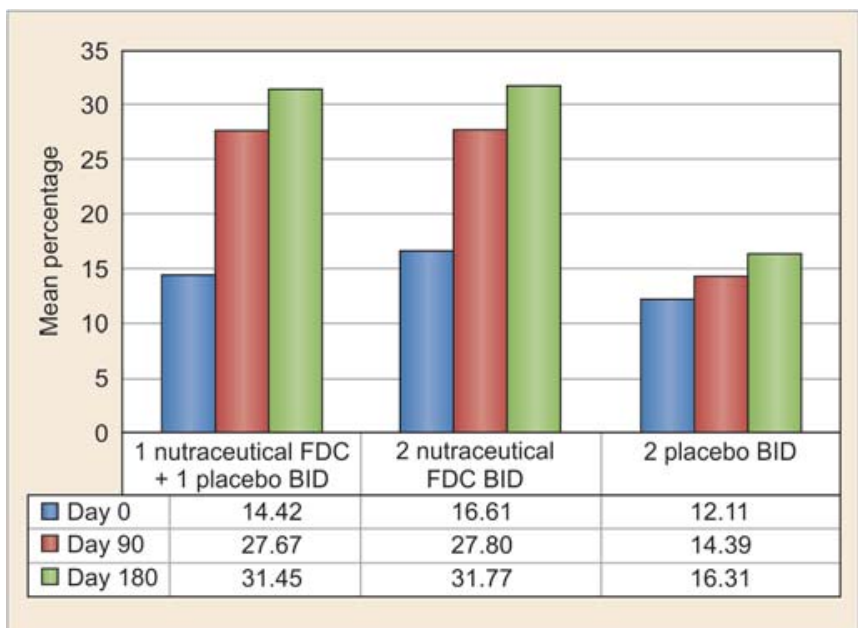

Fig. 4: Sperm with rapid progression WHO A (\%)

\begin{tabular}{|c|c|c|c|c|c|c|c|}
\hline \multirow[t]{2}{*}{ Treatment group } & \multirow[t]{2}{*}{$N$} & \multicolumn{2}{|c|}{ Age (years) } & \multicolumn{2}{|c|}{ Height $(\mathrm{cm})$} & \multicolumn{2}{|c|}{ Weight $(\mathrm{kg})$} \\
\hline & & Mean $\pm S D$ & Range & Mean $\pm S D$ & Range & Mean $\pm S D$ & Range \\
\hline Arm 1 & 46 & $32 \pm 4$ & $22-40$ & $166 \pm 7$ & 149-181 & $70 \pm 13$ & $52-105$ \\
\hline Arm 2 & 43 & $30 \pm 5$ & $22-45$ & $168 \pm 6$ & $156-185$ & $68 \pm 11$ & $45-99$ \\
\hline Arm 3 & 36 & $30 \pm 5$ & $22-41$ & $165 \pm 5$ & $156-176$ & $65 \pm 10$ & $48-95$ \\
\hline All & 125 & $31 \pm 5$ & $22-45$ & $166 \pm 6$ & $149-185$ & $68 \pm 11$ & $45-105$ \\
\hline
\end{tabular}

\begin{tabular}{|c|c|c|c|c|c|c|c|}
\hline \multirow[t]{2}{*}{$\begin{array}{l}\text { Seminal } \\
\text { parameters }\end{array}$} & \multirow[t]{2}{*}{ Day } & \multirow{2}{*}{$\begin{array}{l}\text { Arm } 1 \\
2 \text { FDC tablets } \\
\text { BID }(n=46)\end{array}$} & \multirow{2}{*}{$\begin{array}{l}\text { Arm } 2 \\
1 \text { FDC + } \\
1 \text { placebo } \\
\text { BID }(n=43)\end{array}$} & \multirow{2}{*}{$\begin{array}{l}\text { Arm } 3 \\
2 \text { placebo } \\
\text { BID } \\
(n=36)\end{array}$} & \multicolumn{3}{|c|}{$\begin{array}{l}p \text {-value on comparison with day } 0 \\
\text { value using ANCOVA test }\end{array}$} \\
\hline & & & & & Arm 1 & Arm 2 & Arm 3 \\
\hline Sperm count & 0 & $14.81 \pm 6.08$ & $14.37 \pm 4.39$ & $12.86 \pm 4.98$ & & & \\
\hline \multirow{2}{*}{$(\mathrm{M} / \mathrm{ml})$} & 90 & $26.35 \pm 8.85$ & $24.88 \pm 7.03$ & $14.89 \pm 5.86$ & $<0.0001$ & $<0.0001$ & 0.0134 \\
\hline & 180 & $33.16 \pm 12.35$ & $31.65 \pm 9.71$ & $15.85 \pm 7.73$ & $<0.0001$ & $<0.0001$ & 0.0233 \\
\hline \multicolumn{8}{|l|}{ Motile sperms } \\
\hline \multirow{2}{*}{$(\%)$} & 90 & $51.62 \pm 13.04$ & $50.12 \pm 11.34$ & $42.14 \pm 10.64$ & $<0.0001$ & $<0.0001$ & 0.0381 \\
\hline & 180 & $57.35 \pm 14.61$ & $55.78 \pm 11.94$ & $44.06 \pm 9.53$ & $<0.0001$ & $<0.0001$ & 0.0055 \\
\hline \multicolumn{8}{|l|}{$\begin{array}{l}\text { Sperm with } \\
\text { rapid progression }\end{array}$} \\
\hline \multirow[t]{3}{*}{ WHO A (\%) } & 0 & $16.61 \pm 12.35$ & $14.42 \pm 11.32$ & $12.11 \pm 10.67$ & & & \\
\hline & 90 & $27.80 \pm 15.55$ & $27.67 \pm 14.59$ & $14.39 \pm 12.29$ & $<0.0001$ & $<0.0001$ & 0.0568 \\
\hline & 180 & $31.77 \pm 19.04$ & $31.45 \pm 15.93$ & $16.31 \pm 13.82$ & $<0.0001$ & $<0.0001$ & 0.0005 \\
\hline \multicolumn{8}{|l|}{$\begin{array}{l}\text { Sperm with } \\
\text { slow progression }\end{array}$} \\
\hline \multirow[t]{3}{*}{ WHO B (\%) } & 0 & $12.52 \pm 7.26$ & $16.81 \pm 9.18$ & $17.58 \pm 9.35$ & & & \\
\hline & 90 & $14.42 \pm 8.80$ & $15.00 \pm 7.56$ & $16.64 \pm 8.58$ & 0.0927 & 0.2022 & 0.2485 \\
\hline & 180 & $15.70 \pm 8.15$ & $14.93 \pm 8.01$ & $16.57 \pm 7.68$ & 0.0023 & 0.2324 & 0.1770 \\
\hline No. of pregnancy & & 6 & 7 & 2 & & & \\
\hline
\end{tabular}

M: Million; BID: Twice daily; $p$-value $<0.05$ indicates significant difference wrt day 0 (baseline) 
8 subjects (three in arm 1; one in arm 2 and four in arm 3) were reported.

\section{DISCUSSION}

Deleterious effects of reactive oxygen species and other oxidant molecules on sperm motility and membrane integrity have been well documented. ${ }^{7,8,37-41}$ Studies have also reported the reduced total oxyradical scavenging capacity of seminal fluid in infertile men with abnormal semen parameters. ${ }^{16,42-44}$

Various antioxidants such as CoQ10, L-carnitine, zinc, lycopene, glutathione, etc. have been reported useful in poor semen quality and male infertility. ${ }^{45-51}$ Recently, various double-blind controlled studies have shown effectiveness of individual agents in selected cases of male infertility and

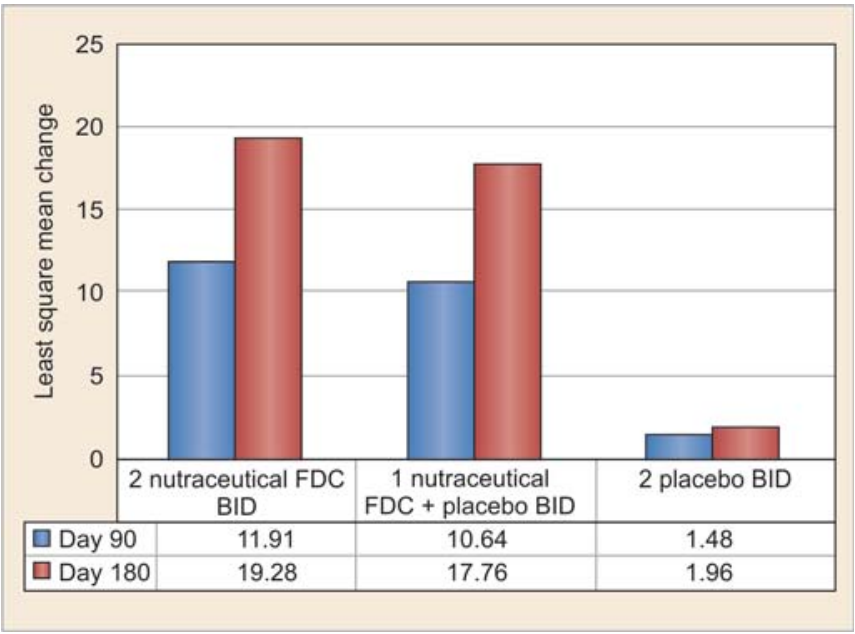

Fig. 5: Improvements in sperm count (million/ml) from baseline suggested therapeutic usefulness of these therapies. ${ }^{24-34}$ However, so far no trial have evaluated the usefulness of these agents when used in combination and especially in Indian population.

Therefore, the current randomized double-blind study evaluated the commercially available FDC of antioxidant on improvements of seminal parameters and its ensuing effect on resultant pregnancy (Figs 5 and 6).

Current study observed over 100\% improvement in sperm count at 180 days over their baseline values in both arms of treatment (Table 2), whereas improvement in sperm count was $23 \%$ with placebo treatment. Antioxidants treatment also significantly $(\mathrm{p}<0.0001)$ improved the sperm motility during the 6 months of administration. At 90 days, motile sperm were increased by approximately $26 \%$ over

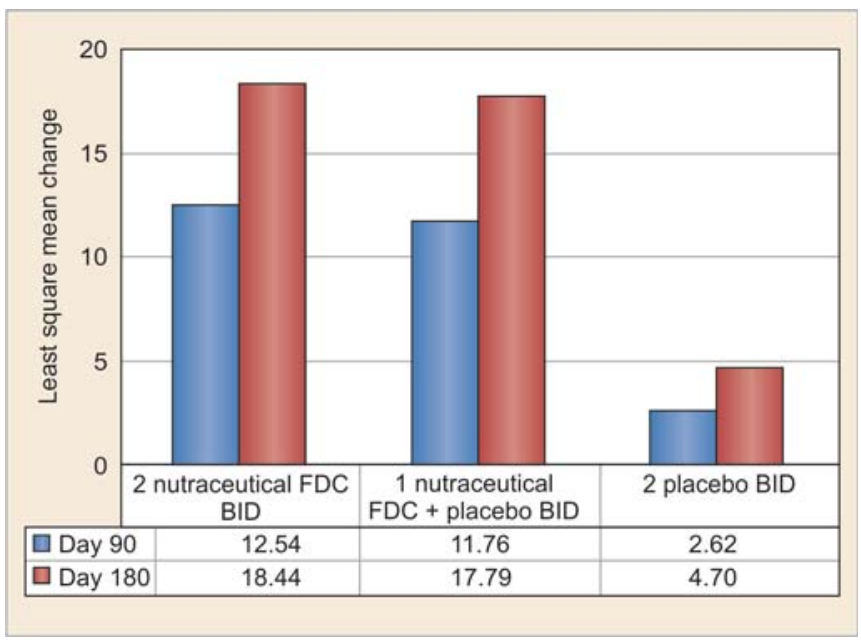

Fig. 6: Improvements in motile sperm (\%) from baseline

Table 3: Intergroup analysis on change (LS mean) of seminal parameters from baseline (day 0) to days 90 and 180

\begin{tabular}{|c|c|c|c|c|c|c|c|c|}
\hline \multirow{2}{*}{$\begin{array}{l}\text { Seminal } \\
\text { parameter }\end{array}$} & \multirow[t]{2}{*}{ Day } & \multirow{2}{*}{$\begin{array}{l}\text { Treatment } \\
\quad \text { arm }\end{array}$} & \multirow[t]{2}{*}{$N$} & \multirow[t]{2}{*}{$L S$ mean $\pm S E$} & \multirow[t]{2}{*}{ All } & \multicolumn{3}{|c|}{$p$-value } \\
\hline & & & & & & $\begin{array}{l}\text { Arm } 1 \\
\text { vs } 3\end{array}$ & $\begin{array}{l}\text { Arm } 2 \\
\text { vs } 3\end{array}$ & $\begin{array}{l}\text { Arm } 1 \\
\text { vs } 2\end{array}$ \\
\hline \multirow[t]{6}{*}{ Sperm count $(\mathrm{M} / \mathrm{ml})$} & Day 90 & Arm 1 & 46 & $11.91 \pm 1.03$ & $<0.0001$ & $<0.0001$ & $<0.0001$ & 0.3908 \\
\hline & & Arm 2 & 43 & $10.64 \pm 1.06$ & $<0.0001$ & $<0.0001$ & $<0.0001$ & 0.3908 \\
\hline & & Arm 3 & 36 & $1.48 \pm 1.16$ & & & & \\
\hline & Day 180 & Arm 1 & 46 & $19.28 \pm 1.58$ & $<0.0001$ & $<0.0001$ & $<0.0001$ & 0.5035 \\
\hline & & Arm 2 & 43 & $17.76 \pm 1.63$ & $<0.0001$ & $<0.0001$ & $<0.0001$ & 0.5035 \\
\hline & & Arm 3 & 36 & $1.96 \pm 1.76$ & & & & \\
\hline \multirow[t]{6}{*}{ Motile sperms (\%) } & Day 90 & Arm 1 & 46 & $12.54 \pm 1.27$ & $<0.0001$ & $<0.0001$ & 0.0003 & 0.3295 \\
\hline & & Arm 2 & 43 & $11.76 \pm 1.30$ & $<0.0001$ & $<0.0001$ & 0.0003 & 0.3295 \\
\hline & & Arm 3 & 36 & $2.62 \pm 1.43$ & & & & \\
\hline & Day 180 & Arm 1 & 46 & $18.44 \pm 1.56$ & $<0.0001$ & $<0.0001$ & $<0.0001$ & 0.466 \\
\hline & & Arm 2 & 43 & $17.79 \pm 1.62$ & $<0.0001$ & $<0.0001$ & $<0.0001$ & 0.466 \\
\hline & & Arm 3 & 36 & $4.70 \pm 1.73$ & & & & \\
\hline \multirow{7}{*}{$\begin{array}{l}\text { Sperm with rapid } \\
\text { progression: WHO A (\%) }\end{array}$} & & & & & & & & \\
\hline & Day 90 & Arm 1 & 46 & $10.77 \pm 1.36$ & $<0.0001$ & $<0.0001$ & $<0.0001$ & 0.7930 \\
\hline & & Arm 2 & 43 & $11.28 \pm 1.39$ & $<0.0001$ & $<0.0001$ & $<0.0001$ & 0.7930 \\
\hline & & Arm 3 & 36 & $2.21 \pm 1.53$ & & & & \\
\hline & Day 180 & Arm 1 & 46 & $15.15 \pm 1.66$ & $<0.0001$ & 0.0002 & $<0.0001$ & 0.7514 \\
\hline & & Arm 2 & 43 & $15.91 \pm 1.72$ & $<0.0001$ & 0.0002 & $<0.0001$ & 0.7514 \\
\hline & & Arm 3 & 36 & $5.52 \pm 1.86$ & & & & \\
\hline
\end{tabular}

$\mathrm{N}$ : Number of subjects; LS mean: Least square mean of change from baseline; SE: Standard error; $p$-value $<0.05$ indicates significant at $5 \%$ level 
baseline in both arms of treatment and by $38 \%$ in 2 tablets twice-daily arm, and $43 \%$ in 1 tablet twice-daily arm at 180 day of treatment as compared to only of 10 and $12 \%$ with placebo at days 90 and 180 respectively (Tables 2 and 3).

Three times more pregnancies seen with antioxidant FDC treatment over the placebo treatment in the current study suggests that the positive benefits of therapy on seminal parameters have desired consequent clinical benefits on pregnancy outcome (Table 2).

Though the results of the current study cannot be directly compared with the previous studies on individual agents, ${ }^{24-34}$ however they are in their close confirmation. A direct correlation among these parameters was not proved, a positive dependence was evident with use of Cramer's index of association. The seminal plasma or intracellular variations of CoQ10 have been positively related to the improvement of the kinetic parameters of sperm cells, with a statistically significant dependence. ${ }^{15,16}$

As recommended in management of male subfertility with antioxidants study observed comparable results with two dosage regimens; i.e. 2 tablets twice daily or 1 tablet twice daily against all primary and secondary efficacy end points. The comparable efficacy of two different dosage regimen observed in the study, is perhaps results of relatively low body weight of participants in this study of Indian population.

The FDC formulation appears to be largely safe, since very few mild adverse events like upper gastrointestinal discomfort reported in treatment groups got self-resolved without discontinuation of therapy and were similar to the type and frequency as of in placebo group. Very low adverse events in current study could be due to demographic variation and dietary habits in India, as approximately $75 \%$ of the body stores of L-carnitine are derived from the dietary sources.

The data of this placebo-controlled, double-blind randomized trial confirm a significant improvement of sperm cell kinetic features after 3 and 6 months of administration of fixed dose nutraceutical combination on the basis of both manual semen analysis.

Our future research work should explore how oxidative stress affects subfertility, male reproductive health and how health affects reproduction.

\section{CONCLUSION}

The commercially available FDC of antioxidative nutraceuticals of CoQ10, lycopene, L-carnitine and zinc significantly impart therapeutic benefits in oligospermia and asthenozoospermia in male subfertility. The FDC is quite safe and the dosage of 1 tablet twice daily may be used in subjects with lower body weight instead of 2 tablets twice daily. So far this is the largest RCT on male subfertility on any combinational nutraceutical intervention that highlight the usefulness of antioxidants in oligoasthenozoospermia.

\section{ACKNOWLEDGMENTS}

All of the authors were responsible for the collection, analysis and interpretation of the data presented in the manuscript. All of the authors have read and approved the final manuscript. The authors would like to thank Zydus Nutriva (A division of Cadila Healthcare Ltd, Ahmedabad) for providing the test and placebo tablets in a blinded manner.

\section{REFERENCES}

1. Myrskylä M, Kohler HP, Billari FC. Advances in development reverse fertility declines. Nature 2009;460:741-43.

2. Lutz W. Fertility rates and future population trends: Will Europe's birth rate recover or continue to decline? Int J Androl 2006;29:25-33.

3. Sharlip I, Jarow J, Belker A, Lipshultz L, Sigman M, Thomas A, et al. Best practice policies for male infertility. Fertil Steril 2002;77:873-82.

4. Thonneau P, Marchand S, Tallec A, Ferial ML, Ducot B, Lansac $\mathrm{J}$, et al. Incidence and main causes of infertility in a resident population $(1,850,000)$ of three French regions (19881989). Hum Reprod 1991;6:811-16.

5. Bunge RG, Keettel WC, Sherman JK. Clinical use of frozen semen; report of four cases. Fertil Steril 1954;5(6):520-29.

6. Dohle GR, Jungwirth A, Colpi G, Giwercman A, Diemer T, Hargreave TB. European Association of Urology. Guidelines on male infertility. Accessed on: May 29, 2012. Available from: http://www.uroweb.org/fileadmin/user_upload/Guidelines/ 13\%20Male\%20Infertility.pdf

7. Aitken RJ, Clarkson JS, Fishel S. Generation of reactive oxygen species, lipid peroxidation and human sperm function. Biol Reprod 1989;40:183-97.

8. Rao B, Soufir JC, Martin M, David G. Lipid peroxidation in human spermatozoa as related to midpiece abnormalities and motility. Gamete Res 1989;24:127-34.

9. Karlsson J. Heart and skeletal muscle ubiquinone or CoQ10 as protective agent against radical formation in man. Adv Myochem 1987;1:305-08.

10. Ernster L, Forsmark-Andree P. Ubiquinol: An endogenous antioxidant in aerobic organisms. Clin Invest 1993;71:60-65.

11. Kalen A, Appelkvist EL, Chojnaki T, Dallner G. Nonaprenyl4-hydroxibenzoate transferase, an enzyme involved in ubiquinone biosynthesis in endoplasmic reticulum-Golgi system. J Biol Chem 1990;25:1158-64.

12. Mancini A, De Marinis L, Oradei A, Hallgass E, Conte G, Pozza D, et al. Coenzyme Q10 concentration in normal and pathological human seminal fluid. J Androl 1994;15:591-94.

13. Alleva R, Tomassetti M, Battino M, Curatola G, Littarru G, Folkers K. Role of CoQ10 in preventing peroxidation of LDL subfraction. Proc Natl Acad Sci USA 1995;92:9388-91.

14. Mancini A, Conte G, Milardi D, De Marinis L, Littarru G. Relationship between sperm cell ubiquinone and seminal parameters in subjects with and without varicocele. Andrologia 1998;30:1-4.

15. Balercia G, Arnaldi G, Fazioli F, Serresi M, Alleva R, Mancini A, et al. Coenzyme Q10 levels in idiopathic and varicoceleassociated asthenozoospermia. Andrologia 2002;34:107-11. 
16. Balercia G, Mantero F, Armeni T, Principato G, Regoli F. Oxyradical scavenging capacity toward different reactive species in seminal plasma and sperm cells. A possible influence on kinetic parameters. Clin Chem Lab Med 2003;41:13-19.

17. Mancini A, De Marinis L, Littarru GP, Balercia G. An update of coenzyme Q10 implications in male infertility: Biochemical and therapeutic aspects. Biofactors 2005;25:165-74.

18. Moradi M, Moradi A, Alemi M, Ahmadnia H, Abdi H, Ahmadi A, et al. Safety and efficacy of clomiphene citrate and L-carnitine in idiopathic male infertility. Urol J 2010;7:188-93.

19. Adel RA, Abd-Allah ARA, Helal GK, Al-Yahya AA, Aleisa AM, Al-Rejaie SS, et al. Pro-inflammatory and oxidative stress pathways which compromise sperm motility and survival may be altered by L-carnitine. Oxid Med Cell Long 2009;2:73-81.

20. Ahmed SD, Karira KA, Jagdesh, Ahsan S. Role of L-carnitine in male infertility. J Pak Med Assoc 2011;61(8):732-36.

21. Wang Y, Aggrawal A, et al. Importance of reactive oxygen species in the peritoneal fluid of women with endometriosis or idiopathic infertility. Fertil Steril 1997;68:826-30.

22. Di Mascio P, Kaiser S. Sies H. Lycopene as the most efficient biological cartenoid singlet oxygen quencher. Arch Biochem Biophys 1989;274:532-38.

23. Colagar AH, Marzony ET, Chaichi MJ. Zinc levels in seminal plasma are associated with sperm quality in fertile and infertile men. Nutr Res 2009;29(2):82-88.

24. Balercia G, Buldreghini E, Vignini A, Tiano L, Paggi F, Amoroso $\mathrm{S}$, et al. Coenzyme Q10 treatment in infertile men with idiopathic asthenozoospermia: A placebo-controlled, double-blind randomized trial. Fertil Steril 2009;91(5):1785-92.

25. Safarinejad MR. Efficacy of coenzyme Q10 on semen parameters, sperm function and reproductive hormones in infertile men. J Urol 2009;182(1):237-48.

26. Tang KF, Xing Y, Wu CY, Liu RZ, Wang XY, Xing JP. Tamoxifen combined with coenzyme Q10 for idiopathic oligoasthenospermia. Zhonghua Nan Ke Xue 2011;17(7):615-18.

27. Nadjarzadeh A, Sadeghi MR, Amirjannati N, Vafa MR, Motevalian SA, Gohari MR, et al. Coenzyme Q10 improves seminal oxidative defense but does not affect on semen parameters in idiopathic oligoasthenozoospermia: A randomized double-blind, placebo controlled trial. J Endocrinol Invest 2011;34(8):e224-28.

28. Costa M, Canale D, Filicori M, D’lddio S, Lenzi A. L-carnitine in idiopathic asthenozoospermia: A multicenter study. Italian Study Group on Carnitine and Male Infertility. Andrologia 1994; 26(3):155-59.

29. Lenzi A, Lombardo F, Sgrò P, Salacone P, Caponecchia L, Dondero F, et al. Use of carnitine therapy in selected cases of male factor infertility: A double-blind crossover trial. Fertil Steril 2003;79(2):292-300.

30. Sigman M, Glass S, Campagnone J, Pryor JL. Carnitine for the treatment of idiopathic asthenospermia: A randomized, doubleblind, placebo-controlled trial. Fertil Steril 2006;85(5):1409-14.

31. Gupta NP, Kumar R. Lycopene therapy in idiopathic male infertility—a preliminary report. Int Urol Nephrol 2002;34(3): 369-72.

32. Goyal A, Chopra M, Lwaleed BA, Birch B, Cooper AJ. The effects of dietary lycopene supplementation on human seminal plasma. BJU Int 2007;99(6):1456-60.

33. Wong WY, Merkus HM, Thomas CM, Menkveld R, Zielhuis GA, Steegers-Theunissen RP. Effects of folic acid and zinc sulfate on male factor subfertility: A double-blind, randomized, placebo-controlled trial. Fertil Steril 2002;77(3):491-98.
34. Ebisch IM, Pierik FH, DE Jong FH, Thomas CM, SteegersTheunissen RP. Does folic acid and zinc sulphate intervention affect endocrine parameters and sperm characteristics in men? Int J Androl 2006;29(2):339-45.

35. World Health Organization. Laboratory manual for examination of semen and semen-cervical mucus interaction (4th ed). New York: Cambridge University Press 1999;60-63 (Appendix IA and IB).

36. WHO laboratory manual for the examination and processing of human semen (5th ed) (page no. 238-41) (Appendix I). WHO Library Cataloguing 0020. http://whqlibdoc.who.int/ publications/2010/9789241547789_eng.pdf

37. Aitken RJ, Clarkson JS. Cellular basis of defective sperm function and its association with the genesis of reactive oxygen species by human spermatozoa. J Reprod Fertil 1987;81:459-69.

38. Suleiman SA, Ali ME, Zaki ZM, El-Malik EM, Nasr MA. Lipid peroxidation and human sperm motility: Protective role of vitamin E. J Androl 1996;17:530-37.

39. Aitken RJ, Krausz C. Oxidative stress, DNA damage and the Y chromosome. Reproduction 2001;122:497-506.

40. Aitken RJ, Baker MA. Reactive oxygen species generation by human spermatozoa: A continuing enigma. Int J Androl 2002;25: 191-94.

41. Balercia G, Moretti S, Vignini A, Magagnini M, Mantero F, Boscaro M, et al. Role of nitric oxide concentration on human sperm motility. J Androl 2004;25:245-49.

42. Sekine K, Ota N, Nishii M, Uetake T, Shimadzu M. Estimation of plasma and saliva levels of coenzyme Q10 and influence of oral supplementation. Biofactors 2005;25:205-11.

43. Lewis S, Boyle P, McKinney MB, Young I, Thompson W. Total antioxidant capacity of seminal plasma is different in fertile and infertile men. Fertil Steril 1995;64:868-70.

44. Rhemrev JP, Van Overveld FW, Haenen GR, Teerlink T, Bast A, Vermeiden JP. Quantification of the nonenzymatic fast and slow TRAP in a postaddition assay in human seminal plasma and the antioxidant contribution of various seminal compounds. J Androl 2000;21:913-20.

45. Moncada ML, Vicari E, Cimino C, Calogero AE, Mongio A, D’Agata R. Effect of acetylcarnitine treatment in oligoasthenospermic patients. Acta Eur Fertil 1992;23:221-24.

46. Sikka SC, Rajasekaran M, Hellstrom WJG. Role of oxidative stress and antioxidant in male infertility. J Androl 1995;16:464-68.

47. Vitali G, Parente R, Melotti C. Carnitine supplementation in human idiopathic asthenozoospermia: Clinical results. Drugs Exp Clin Res 1995;21:157-59.

48. Ford WCL, Whittington K. Antioxidant treatment for male subfertility: A promise that remains unfulfilled. Hum Reprod 1998;13:1416-19.

49. Geva E, Lessing JB, Lerner-Geva L, Amit A. Free radicals, antioxidants and human spermatozoa: Clinical implications. Hum Reprod 1998;13:1415-24.

50. Tarin JJ, Brines J, Cano A. Antioxidants may protect against infertility. Hum Reprod 1998;13:1415-16.

51. Showell MG, Brown J, Yazdani A, Stankiewicz MT, Hart RJ. Antioxidants for male subfertility. Cochrane Database Syst Rev 2011;19(1):CD007411.

\section{ABOUT THE AUTHORS}

\section{PM Gopinath}

Senior Consultant, Department of Gynecology, Sooriya Hospital Chennai, Tamil Nadu, India 


\section{Bharti Kalra}

Senior Consultant, Department of Gynecology, Bharti Research Institute of Diabetes and Endocrinology (BRIDE), Karnal, Haryana, India

\section{Ajit Saxena}

Senior Consultant, Department of Andrology, Menz Health Clinic Noida, Uttar Pradesh, India

\section{Sonia Malik}

Senior Consultant, Department of Gynecology, Southend Fertility and IVF Centre, Holy Angels Hospital, Vasant Vihar, New Delhi India

\section{Kapil Kochhar}

Senior Consultant, Department of Andrology, Men’s Health Clinic Indore, Madhya Pradesh, India

\section{Sanjay Kalra}

Senior Consultant, Department of Endocrine, Bharti Research Institute of Diabetes and Endocrinology (BRIDE), Karnal, Haryana, India

\section{Hemant Zaveri (Corresponding Author)}

Fellow, Department of Faculty of Medicine, Gujarat University, Ahmedabad, Gujarat, India, Phone: 91-8128686365 e-mail: drhemantzaveri@gmail.com 